Understanding setting-empowerment

Understanding how engagement in a self-managed shelter contributes to empowerment

Max A. Huber ${ }^{1}$, Louis D. Brown ${ }^{2}$, Rosalie N. Metze ${ }^{1}$, Martin Stam ${ }^{1}$, Tine Van Regenmortel ${ }^{3}$, Tineke N. Abma ${ }^{4}$

Published in: Journal of community \& applied social psychology (final accepted version), spring 2020, http://dx.doi.org/10.1002/casp.2460

${ }^{1}$ Research center for Societal Innovation, Amsterdam University of Applied Sciences

${ }^{2}$ School of Public Health, University of Texas

${ }^{3}$ Academic collaborative center for social work, Tilburg University \& HIVA - Research Institute for Work and Society, Catholic University Leuven

${ }^{4}$ Department of Medical Humanities, Free University Amsterdam

Correspondence concerning this article should be addressed to Max Huber, Research center for

Societal Innovation, Amsterdam University of Applied Sciences, Wibautstraat 5, $1091 \mathrm{GH}$, Amsterdam, The Netherlands. Contact: a.huber@hva.nl 
Understanding setting-empowerment

\begin{abstract}
Participant empowerment is a foundational goal of self-organized homeless care. We aim to understand how a self-organized setting contributes to participants' empowerment. The data we analyzed (56 interviews, both open and semi-structured) were generated in a longitudinal participatory case-study into Je Eigen Stek (Your own place, JES), a low-cost shelter for people experiencing homelessness in the Netherlands. JES participants experienced freedom of choice and influence on their living environment. JES' fluid structure allowed participants to adapt the program to their desires and needs, though participants were sometimes negative about having to live together. Most participants preferred JES over regular shelters. Unlike empowerment literature, participants mostly emphasized freedom of choice over capacity development. JES offered opportunities for social and organizational engagement, through which participants developed roles, skills and self-image. However, a limited number of participants developed leadership roles through self-management. Literature suggests setting aspects to be either enabling or entrapping. We found some aspects (e.g. size, freedom of choice) could be entrapping or enabling, depending on personal factors. Our analysis revealed individual freedom of choice, balancing freedom of choice with support, offering opportunities for engagement and maintaining fluidity in program management as core aspects of how JES contributed to participants' empowerment.
\end{abstract}

Keywords : Self-management; self-organized care; empowerment; homelessness; social work; peer work; empowering-setting 
Understanding setting-empowerment

\section{Understanding how engagement in a self-managed shelter contributes to empowerment Introduction}

People experiencing homelessness started self-managed shelters to offer empowerment opportunities for participants (Tuynman \& Huber, 2014). Participants and peer workers in a selfmanaged shelter control both daily affairs and strategic decisions (Tuynman \& Huber, 2014). Self-managed shelters are a form of self-organized care (Brown, 2012), like mutual help (Hatzidimitriadou, 2002), mental health consumer run centers (Brown, 2012) and peer run respite houses (Ostrow \& Croft, 2015), all associated with empowerment of participants (Brown, 2012; Ostrow \& Croft, 2015). In this paper we aim to understand how a self-managed homeless shelter as a setting can contribute to participants' empowerment.

\section{Homelessness}

People who are homeless experience a combination of financial problems, problems with mental health, substance abuse and / or social exclusion. These problems are both the cause of and caused by being homeless (Padgett et al., 2016; Van Der Laan et al., 2018; Van Regenmortel et al., 2006). Homelessness is on the rise in the Netherlands, in part caused by a shortage in affordable housing (Trimbos, 2019). Not being able to access affordable housing contributes to disempowerment of people experiencing homelessness (Van Der Laan et al., 2018). Selfmanaged shelters were started as an alternative to regular shelters, that are seen as disempowering because they lack of attention for freedom of choice and capacity development (Padgett et al., 2016; Van Regenmortel et al., 2006). Self-managed shelters share with Housing First an emphasis on self-determination and the absence of pre-conditions (Padgett, Henwood, \& Tsemberis, 2016). Self-managed shelters reach people who are not (yet) able to access a Housing first program (Tuynman \& Huber, 2014). 
Understanding setting-empowerment

\section{Self-management and self-organized care}

Self-managed shelters support participants towards permanent housing (Tuynman \& Huber, 2014). Self-managed shelters per-person cost is lower than similar professionallymanaged shelters in the Netherlands (Tuynman \& Huber, 2014). There are a few active selfmanaged shelters in the Netherlands (Tuynman \& Huber, 2014). Self-organized care is associated with participants empowerment, specifically through development of roles, relations, skills and self-image (Brown, 2012). Participants who are less engaged with activities and program management, experience fewer benefits (Brown, 2012; Segal \& Hayes, 2016). Peer support in general is associated with empowerment (Barker et al., 2018).

\section{Empowerment}

Empowerment is argued to be a paradigm, entailing vision, process and outcome, on a psychological, collective, organizational and political level ((Van Regenmortel, 2011). According to Rappaport (1981), empowerment is a dialectical concept, balancing freedom of choice and capacity development. Others emphasize capacity development, arguing that it contributes to the ability of individuals and communities to gain influence (Van Regenmortel, 2011; Zimmerman, 1995). In recent years, developing self-sufficiency and self-improvement, aspects of psychological empowerment, have evolved into public policy and a social norm, in the Netherlands and elsewhere (Abma, 2017; Rivest \& Moreau, 2015). Becoming self-sufficient as an obligation rather than as emancipation, goes against empowerment principles (Peterson \& Zimmerman, 2004; Rappaport, 1987) and, combined with budget cuts in social support, risks neglecting people in a vulnerable position (Abma, 2017). Participation in empowerment practices by individuals in a vulnerable position might be hindered by barriers such as a lack of skills or resources (Boone et al., 2019). 
Understanding setting-empowerment

\section{Empowering settings}

Both in practice and research, most attention is given to psychological empowerment (Van Regenmortel, 2011; Zimmerman, 1995). Psychological empowerment entails "a sense of personal control or influence and a concern with actual social influence" (Rappaport, 1987, p.

121). It is argued that psychological empowerment is only possible in a social environment (other people, organizational context, community) that enables empowerment, by offering supportive social relations, opportunities for individual development, and an empowering collective identity (Peterson \& Zimmerman, 2004; Speer \& Hughey, 1996; Van Regenmortel, 2011). The other way around, community or organizational empowerment describes how individuals influence their situation through an organization or community and the influence individuals have on an organization/community (Peterson \& Zimmerman, 2004; Maton, 2008). Self-organized care can be seen as an example of how a setting can contribute to empowerment (Brown, 2012). To understand how consumer run centers contribute to empowerment, Brown (2012) developed a role framework (see Figure 1), which describes how through person-environment interaction in self-organized care settings, participants are drawn into empowering roles, through which participants develop relations, role-skills, their self-image and their identity. 


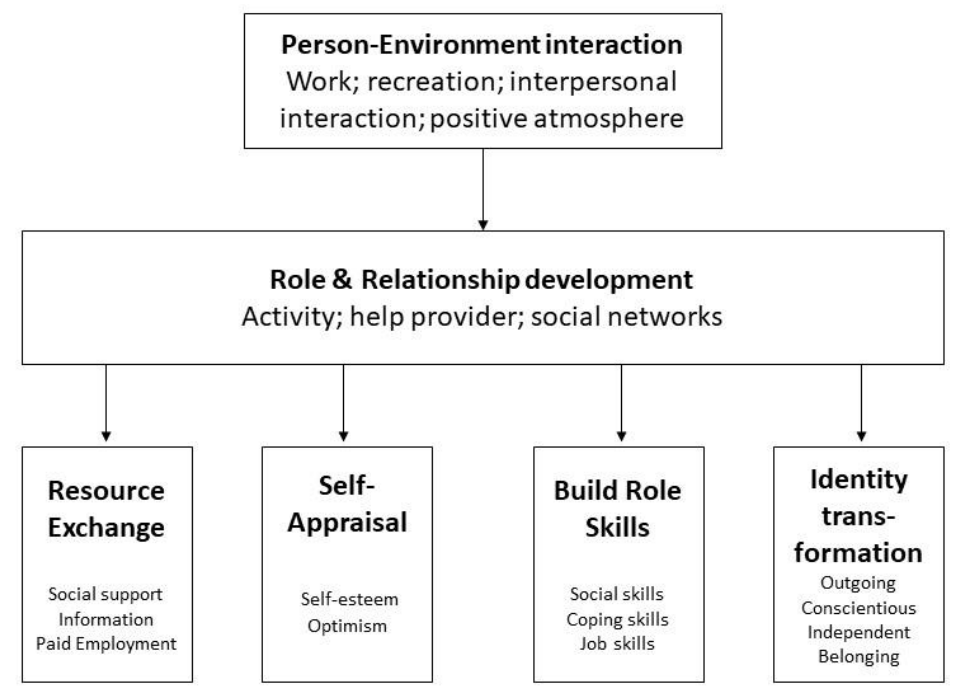

Figure 1: Brown's role-framework (2012, p. 42)

In addition, Maton's (2008) empowering community setting highlights a shared vision on empowerment, diversity in role opportunities, leadership and a learning organization.

Organizational empowerment (Peterson \& Zimmerman, 2004) emphasizes the importance of an empowered organization in relation to other organizations and society. Taylor's (1997) enabling niches focusses on identity development and adds a counterpart, an entrapping niche, associated with stigma, social exclusion and a lack of growth opportunities. The influence from a setting on behavior can be perceived as negative, a form of social discipline (Scott, 2010). Renedo \& Marston (2015) argue for the importance of space for developing participation and engagement. Especially in institutional care settings such as a self-managed homeless shelter, where participants live and work together, space can be an important factor (Wolins \& Wozner, 1982).

Building on the role-framework theory, enriched with other discussed theory, we aim to answer the question: how can the setting of a self-managed shelter contribute to participant empowerment? 
Understanding setting-empowerment

\section{Method}

The empirical data was gathered in a longitudinal (2009-2016) participatory case study (Abma \& Stake, 2014) into empowerment processes in Je Eigen Stek (Your own place, JES), a self-managed shelter, as part of the Collaborative Center for the Social Domain (Werkplaats sociaal domein) at the Amsterdam University of Applied Sciences.

We followed the principles of responsive evaluation (Abma et al., 2009). Stakeholders were engaged in the evaluation process and their issues with regards to self-management formed the starting point for a dialogue to develop mutual understanding and articulate different perspectives.

\section{Study Setting}

JES wants "to help people without a home, get a home", offering shelter for people who want to work on their own problems in their own way. JES serves people who are unable to obtain independent housing, because of financial or personal problems. Potential participants have to be able to take care of themselves. Most participants are dependent on welfare, some have a job. JES houses sixteen people. Participants are responsible for program management, from household to entrance and exit of participants and strategic issues. Participants choose a chairman among themselves, to lead meetings and represent JES in external affairs, together with other participants. JES is funded by the Amsterdam municipality and is part of a mother organization which offers regular homeless care. Unlike most self-organized programs (Brown, 2012), JES hired a social worker to support individual participants, the group and the program. The social worker collaborates with a peer worker, who is a former participant. Both the social worker and the peer worker are paid and both are hired by participants through a vote at a meeting. 
Understanding setting-empowerment

In the first five years of JES (2009-2014), 72 people stayed there, from less than a day up to multiple years. After excluding those who left within a few weeks, the average length of stay is around 15 months. Of the 72 participants, 51 stayed for more than three months, of whom 32 were explicitly spoken to as part of our research (in an interview or through informal meetings). We have (some) secondary information from 17 other residents, such as length of stay and way of leaving. The majority of participants were male and single. Participants were of adult ages, with a few exceptions of late adolescents. JES did not register ethnicity.

\section{Data Collection}

The evaluation has been executed by a diverse research team, including researchers with lived experience. Interviews were held with participants $(\mathrm{N}=27)$, peer workers $(\mathrm{N}=3)$, social workers $(\mathrm{N}=2)$ and other stakeholders (e.g. policy advisors from the mother organization, managers from partner organizations) $(\mathrm{N}=10)$. Several participants, peer workers and social workers were interviewed multiple times, resulting in 56 interviews in total. The interviews come from two sub-projects, 34 from the first, 22 from the second. The first was an exploratory case-study into JES, in 2009-2010. For this project, narrative interviews were held, focused on the experiences of those involved. The interviews explored what participants saw as the purpose of self-management, what their own motivation was, and how they experienced living/ working in self-management. The second sub-project, executed in 2013-2014, focused on how former JES participants looked back on their participation, using a semi-structured format (Bryman, 2008). The interviews with former participants focused on their experiences with JES and on several life domains (e.g. housing, finances, social contacts, day activities) at three points in time (before, during and after their stay at JES). The interviews from the first study were conducted by two academic researchers, one of whom is the first author. The interviews from the second 
Understanding setting-empowerment

study have been done by duos of participants and students, under supervision of academic researchers, one of whom is the first author. All interviews were recorded and transcribed.

In addition to the interviews, documents were analyzed (e.g. project-plans, autopublications by participants such as contributions to research publications) and administrative data recorded by JES on participants demographic background and length of stay was processed, both for contextual information on the program and as secondary information on participants. A social worker and a peer worker from JES participated in four focus groups with social workers and peer workers from other self-managed programs in the Netherlands. Two focus groups where homogeneous, with only social workers or only peer workers, and two focus groups were heterogeneous.

From the first study's start (2009) until the present, based on a participatory approach (Banks et al., 2013; Chandler \& Torbert, 2003), the first author engaged with participants, peer workers and social workers from JES and they engaged with the research. Enabling vulnerable populations, such as people experiencing homelessness, to be heard is an important value of participatory research (Banks et al., 2013; Lincoln \& Guba, 1985). Participants, peer workers, and social workers from JES engaged with co-designing the research, developing topic-lists, recruiting respondents, co-interviewing, discussing the analysis and contributing to publications, to increase our research' authenticity (Lincoln \& Guba, 1985).

The first author made around 60 visits and had numerous informal conversations with participants, social workers and peer workers via mail, telephone and other gatherings (joined visits to meetings, informal drinks). Informal conversations and observations focused on gaining insight into how participants and other stakeholders experienced self-management over time. Developing long lasting relations with participants, peer workers and social workers allowed the 
Understanding setting-empowerment

first author to observe the interaction between participants, peer workers and social workers among themselves and with outsiders (including the researchers) over time. The prolonged engagement and persistent observations (Lincoln \& Guba, 1985) resulted in a deeper understanding of our data.

In our research we have complied with APA ethical principles in the treatment of individuals participating in the research. For this study, executives of participating organizations assessed the study's legal and ethical implications, and approved the procedures. Participants were informed and consented on the research purpose and their ability to withdraw, which was done by one participant, whose interviews were deleted.

\section{Analysis}

The analysis has been executed by the first author, under supervision of the other authors, all with academic background and with extensive expertise on participatory research and qualitative analysis. Throughout the analysis we remained in contact with JES, discussing preliminary analyses and working hypotheses with participants, peer workers and social workers in multiple sessions. This sharpened the analysis and increased the authenticity and a shared understanding of the core findings (Doyle, 2007; Lincoln \& Guba, 1985). For both studies a draft report was discussed with respondents and other stakeholders in focus groups (Lincoln \& Guba, 1985).

We employed an iterative approach, going back and forth between empirical data and theory, combining interpretation and systematic coding, assisted by MAXqda (Abma et al., 2019; O’Reilly, 2012). To manage our large dataset, we started by creating thematic categories, based on preliminary analysis and the described theoretical framework, to guide our focus (O'Reilly, 2012). Based on initial coding, our code list was revised, applied to new interviews and so on, 
Understanding setting-empowerment

until code-saturation was achieved, after which the first interviews were recoded with the final code-tree (Bryman, 2008; O’Reilly, 2012). In our results we indicated whether there was consensus on an issue or not and if not, what the dominant opinion was. Quantifications are not added with respect to the narrative and our research constructivist nature (Abma et al., 2019).

The richness of perspectives and the different theoretical approaches, allowed us to make room for competing explanations (Abma et al., 2009). We strived for an authentic and recognized representation of different perspectives involved with JES (Abma \& Stake, 2014; Lincoln \& Guba, 1985), paying explicit attention to the risk of overrepresenting more reflexive respondents (Bryman, 2008). To improve our research quality, we used several forms of triangulation: different types of data gathering, different researchers and different analytical approaches to limit bias (Denzin, 1989; Kimchi et al., 1991).

Access to datasets is available through the corresponding author on reasonable request.

\section{Results}

Based on our analysis we will discuss participant factors, the interaction between individual and collective self-management, enabling role and relationship development, including limitations to enabling development, leadership and collective interest, fluidity and the role of social workers and peer workers.

The cited quotes are translated from Dutch by the first author. To protect anonymity, the respondents are not numbered. With only few exceptions, most quotes are from different respondents, with varying views.

\section{Participant Factors}


Understanding setting-empowerment

Although the majority of the participants say they have benefited from their engagement with JES, not all have, and those who did, did so in various ways. Participant factors, such as socialization, experiencing homelessness, learned helplessness developed in regular care (Van Regenmortel et al., 2006) and personal preferences, appeared to influence the benefits participants experienced. JES focuses on people who are homeless, do not have serious psychiatric or addiction issues and are willing and able to engage with self-management. In practice, participants and peer workers who met with prospective participants, found it difficult to distinguish suitable participants who could benefit from engagement. Some participants said it was undesirable to filter out prospective participants, because everyone deserved a chance. In practice, most participants joined JES because they were either not able to enter regular homeless shelters or were fed up with the unwanted staff interference and restrictions. The majority of participants preferred JES over a regular shelter.

Experiences of participants fall in three clusters of stories. The first cluster is enthusiastic and engaged with the program, the second is moderate to critical and minimally engaged, the third is mostly negative and disengaged. The three clusters overlap and participants moved from cluster to cluster, e.g. start active, get disappointed and focus on themselves, or get stuck, drop out, come back and become very active.

From 53 of the 72 participants who stayed at JES during the first five years (2009-2014) we have sufficient information to say with some certainty to which cluster they belong. The first cluster (engaged) consisted of 27 (of 53) participants. Ten participants of the first cluster (temporarily) moved to cluster two or three. Members of the first cluster stayed longer at JES than members of the second cluster. The second cluster (moderately critical and minimally engaged) had seventeen members (of 53), four of whom started out in cluster one. The third 
Understanding setting-empowerment

cluster (negative and disengaged) had nineteen members (of 53), of which six started or ended in the first cluster. It is also the cluster of which we know the least, as members of the third cluster typically stayed at JES for less time. Four participants out of this cluster were interviewed and three more have met informally with the first author.

\section{Individual \& Collective Self-management}

All participants got a physical key to the program and their room, which enabled them to leave and enter whenever they wanted, symbolizing their self-management. Participants were able to stay as long as they needed or preferred, having shelter and other basic needs met, which they often did not have before their stay at JES. Most participants, even those who were negative about their experiences with JES, appreciated the time, space and freedom of choice JES offered for participants to work on their problems in their own way. In contrast, JES participants described regular shelters as offering limited freedom of choice and capacity development. JES presumed that participants were able to work through their problems in their own way, although they were able to get individual practical and emotional support, if requested, from other participants, peer workers and social workers.

Some participants were unable to deal with the freedom of choice JES offered and either dropped-out, were pushed out by participants or stopped progressing.

"There were people who did nothing, truly nothing, to improve their situation. They didn't want to move on. They resigned themselves. They had food, they could sleep, could watch television and it cost them almost nothing" (participant).

Other participants only needed a place to stay, to work out their affairs by themselves, and although they benefited from the time and space JES offered them, they did not engage with or benefit from active self-management. Participants, peer workers and social workers struggled 
Understanding setting-empowerment

when dealing with participants who did not benefit and did not ask for support, particularly in terms of balancing freedom of choice with wanting to offer support. Others said all participants had to choose for themselves whether they wanted to use the opportunities JES offered:

"If you're here, you have a roof over your head, you can sleep when you want, eat when you want, so it is up to people what they want. One goes to work, another one says I'm going to sit and watch TV. It's what people want to make out of life" (participant). A majority of participants, belonging to the positive and / or moderate cluster, were positive about being able to influence the program they were living in, together with other participants. The extent to which they actually engaged with the collective self-management process and their practical experiences differed, as we will discuss in the next section. Every Monday evening there was a house meeting with all participants, which was the only place where formal decisions about the program could be made, from household schedule to hiring or firing a social worker. Both the peer worker and the social worker had no formal say, while all participants were able to bring issues to the fore and decide on the issues at hand. Those actively engaged in program management said they felt program ownership and that they were able to influence the program. Engagement in program management resulted in direct influence for participants.

\section{Enabling Roles and Relationships Development}

Participants' ability to develop roles and relationships is at the core of Brown's (2012) framework. Some respondents appreciated the relational environment at JES, describing how they enjoyed casual interaction in front of the TV, social support from other participants and being part of a "community" or "family". Through social comparison and social motivation (Brown, 2012) (he can do it, so maybe I can too) participants experienced social learning. A 
Understanding setting-empowerment

participant described how during meetings it was sometimes discussed how participants were

progressing with their issues: "One time, we had a participant who stopped the meeting, walked away, got his stack of mail and stuff and said 'I'm going to work on it right now'. You stimulate each other".

Participants developed experiential knowledge by exchanging their own lived experience, both practical and emotional, with others. Participants who were positive about the relational environment developed social roles and tended to actively engage with the program management, through joining meetings, initiating and contributing to projects and advocating for JES towards the mother organization, other organizations and the municipality.

Engagement with both the relational environment and management contributed to the participants' developing roles, relations, skills and self-image. "It was already in you. Only now it came out. Maybe that is what I have learned, recognizing and acknowledging your own talents" (participant). For multiple participants, engagement with JES was a stepping stone towards an ongoing role in advocacy and/ or towards becoming a peer worker either within JES or at other programs outside JES. Because JES is relatively small, there was little diversity in roles, though various participants stated that they were able to take on a role that suited their interests and abilities.

\section{Limitations to Role and Relationship Development}

Moderate and negative participants engaged less with the relational environment and program management. For them, freedom of choice was self-management' main appeal. They stated their problems were private and were reluctant to share personal issues with other participants. "During meetings there was a lot of talk on personal problems. That is not okay. It 
Understanding setting-empowerment

really isn't. I think the personal life or issues should not be discussed with everyone" (participant).

The motivation for not engaging differed. Some participants viewed the idea of selfmanagement favorably, though they focused on their own life. The distrust of other participants and a reluctance to develop social relations caused some participants to disengage. A few disengaged participants dropped out because they could not adjust to living together, according to other participants, peer workers and social workers. The participants that left themselves said that other participants were lying, that they had been treated unfairly and it was all a "hypocritical mess." Many participants and all peer workers and social workers stated that experiencing long term homelessness, including limited access to basic needs and social exclusion, was a traumatic experience causing participants, in varying degrees, to become distrustful and individualistic. In turn, distrust and individualism, together with pre-existing vulnerabilities in relation to mental health and substance abuse, hindered engagement with the relational environment and program management.

Participants, peer workers and social workers described how participants were sometimes harsh towards each other, partly caused by their homelessness. When conflicts escalated, participants at times decided quite rashly to exclude a participant, according to social workers and peer workers. At other times, issues between participants or between one participant and the group, were not addressed. In both cases, social workers and some peer workers and participants tried to encourage deliberation between participants on how to live together and deal with each other's issues, with varying success. "I hope a situation develops, in which they can talk a bit more, more easy, with each other about being hurt. Where it hurts and what caused it. They feel 
Understanding setting-empowerment

averse to it. 'It is not for us, we don't have that'. [So I suggest] talk about it. Try and find something, to acknowledge it" (social worker).

Participants were often uninterested in deliberation and rather wanted the matter either quickly resolved or ignored. In relation to their own issues participants said they were either nonexistent ("nothing is wrong with me, I only need a house") or that they came to JES to be free from unwanted interference. In cases where participants did exchange insights, ideas and experiences, it often led to mutual understanding and learning.

Living together in an institutional setting, where participants share living space, facilities and in many cases a bedroom, appeared to influence engagement. For some, living together offered opportunities for low threshold social contacts. "If you want to talk to people, you can talk. There is always someone in the living room. You were almost never alone" (participant). Living together also created a sense of urgency to join in program management, which had direct influence on daily life. Others felt there was too little private space and they disengaged from social life and management to prevent conflicts with other participants.

Some felt there were too few house rules (e.g. on chores, nuisance) and they were not sufficiently enforced, while others felt the opposite. Those positive about living together said it contributed to developing roles and relationships, others experienced living together as negative. Social workers and some peer workers and participants stated that living together was beneficial for those who resented living together, because it helped them prepare for social aspects of independent living.

\section{Leadership and Collective Interest}

Both in theory (Brown, 2012; Maton, 2008; Peterson \& Zimmerman, 2004) and our data, we found that the program as a whole could benefit from strong capable leadership, at least in the 
Understanding setting-empowerment

short term. Shared leadership, wherein all participants can take part in the program management, enabled individuals to develop leadership roles and skills, which benefited both these participants and the program. In the short term, shared leadership also had drawbacks, such as indecision on issues that needed attention. While some participants preferred strong leadership, other participants disengaged from the management in periods where there was strong leadership, out of convenience or resistance to the leadership.

"The new group got no chance $[. . .$.$] they behaved like in all shelters; there was no$ ownership, I did not have the feeling they could exercise influence [....] so they did nothing, so the [old] group said 'they're not doing anything'. It must be achieved every time $[\ldots .$.$] the group needs to make space" (social worker).$

The leadership issue illustrates the interaction and tension between individual and collective interests. Individual and collective interests did align in many situations. For instance, when a participant advocated for the program, the program benefited, while the participant developed roles, skills and an improved self-image. Scarcity in capable participants offered opportunities for more participants to take roles, who would normally not have taken them (Brown, 2012; Maton, 2008). 'I started to take the lead, normally I don't do that, I prefer staying in the background, but that didn't work there" (participant).

Some participants focused on their individual life. For participants who were active, seeing other participants not contributing was discouraging. However, inactive participants said that seeing the active participants was encouraging. JES as a program depended on participants contributing to the program, so if there were too few active participants, program development stagnated. However, in those instances, after some time, some participants became active and self-management continued. 
Understanding setting-empowerment

\section{Fluidity}

"I've seen the good, the bad, I've seen it all" (participant). As a consequence of selfmanagement and the dependency on participants, JES appeared dynamic and fluid. Rules and structures were made, changed, discarded and rediscovered, to the some longer term participants dismay, who felt they were having the same discussions over and over. There were multiple instances when tensions arose between an established group of longer term participants and a new group of participants who wanted to shake things up, after which the longer term participants moved on and the new group became the established group, and the process started again.

Four inherent tensions in the program influence JES' fluid and dynamic nature. On an individual level, there is a tension between freedom of choice and encouraging participants to engage with the opportunities JES offered on an individual, relational and collective level (1). There is also a tension between participants supporting each other and participants not wanting or not being able to give and/ or receive support from others (2). On a collective level there is a tension between structure (e.g. house rules, hierarchy) and individual freedom of choice (3), along with a tension between individual interests and a collective interest (4).

Although most participants, peer workers and social workers have their own position in these issues, various respondents acknowledged that trying to make a permanent decision on these issues would limit the opportunities for JES to adapt to the abilities and interests of both individuals and changing groups. Through the ongoing deliberation on these four tensions, participants developed new insights, new skills and mutual understanding. The tensions helped break through rigidity that did occur at times and forced participants, peer workers, social 
Understanding setting-empowerment

workers and others involved to reflect on underlying values of self-management rather than defer to procedures.

\section{Role of Social Workers and Peer Workers}

Social workers often acted indirectly, creating opportunities for participants to engage, focusing on capacities, inducing engagement and suggesting possibilities, rather than directly initiating behavior. Social workers and peer workers emphasized the importance of facilitating participants' critical awareness of their societal situation and their own possibilities to influence their situation, contributing to social action and participant's capacity development. Social workers and some peer workers and participants emphasized the importance of deliberation on and inclusion of struggling participants. Social workers, who worked on the basis of trust from participants who were distrustful, had to balance emphasizing a moral standpoint of inclusion and gaining and maintaining participants trust. A social worker described the participants attitude as: "don't meddle in my affairs, but please do a bit." Social workers and peer workers often hesitated to intervene or employ therapeutic methods, because they were afraid their actions would hurt self-management's principles and processes. Some participants agreed, although others wanted more intervention, especially in relation to participants that were struggling and / or were causing conflicts, even if intervention meant limiting self-management. One consideration for intervening was when it "goes wrong. To prevent that it [participant exclusion] goes too unjust or too harsh" (social worker). Social workers and peer workers weighed different situational aspects, balancing individual and collective interests and self-management's values to decide if and how to intervene.

\section{Discussion}


Understanding setting-empowerment

In this paper we analyzed how a self-managed shelter can contribute to empowerment processes, building on the role-framework (Brown, 2012) and other theory describing the interaction between a setting and empowerment (Maton, 2008; Taylor, 1997).

Brown's role-framework (2012) provided insight into participants' developing roles, relations, skills and self-image. Our findings also support the statement that there is a relation between engagement with the relational environment and program management and (explicit) participant development (Brown \& Townley, 2015; Segal \& Hayes, 2016).

\section{Freedom of choice}

The role-framework focuses on psychological empowerment, and less on freedom of choice (Brown, 2012). For most participants self-management was also or mainly about freedom of choice, an important aspect of empowerment (Rappaport, 1987; Van Regenmortel, 2011). The majority of participants appreciated and benefited from the freedom of choice offered, the time, space and opportunity to work on problems in their own way in a capacity oriented environment.

Some participants used their freedom of choice to disengage from self-management. Social workers, peer workers and participants tried to balance freedom of choice with offering support to participants who appeared to struggle, encouraging them to open up to other participants. The latter was complicated by a fear of psychologizing self-management, held by all involved, which limited their (perceived) ability to support individuals and elicit group discussions on psychological empowerment.

\section{Influence of personal factors}

Most frameworks on empowering settings describe aspects that are either enabling or entrapping (Brown, 2012; Maton, 2008; Peterson \& Zimmerman, 2004; Taylor, 1997). Our analysis revealed aspects that can be either enabling or entrapping, such as an emphasis on 
Understanding setting-empowerment

freedom of choice, unrestricted length of stay and living together. For many participants, these aspects enabled them to work on their problems and develop roles, relations, skills and their selfimage, while for others these same aspects had an entrapping effect. Personal factors influence whether these aspects are enabling or entrapping. Some participants struggled with learned helplessness developed in regular care settings and/ or cognitive disabilities, mental health issues and substance abuse issues. As a consequence, they were less able to self-direct and take care of themselves and struggled to benefit from the opportunities JES offered, although over time, multiple participants developed self-direction through social learning and social motivation. More research is needed to understand personal factors that influence whether an aspect is enabling or entrapping.

\section{The role of a space}

As suggested in the literature (Goffman, 1961; Renedo \& Marston, 2015), living together and managing a space together appeared to influence participant empowerment. Many participants appreciated the literal key to their own place and expressed ownership feelings of the space where the program was housed.. Living together enabled low threshold social contacts and a sense of urgency to engage with program management. Having an actual space to manage offered opportunities for participants to develop roles and skills and improve their self-image. Personal factors influenced how participants experienced living together. Some participants loathed following house rules made by others or desired a high level of structure and rules

Most participants experienced living together and having little private space as limiting their opportunities for freedom of choice. Personal preferences, influenced by experiences such as trauma and social exclusion, appeared to influence participants' willingness to engage with social aspects of self-management. Conflicts caused by living together are also seen in regular 
Understanding setting-empowerment

shelters (Padgett et al., 2016; Van Regenmortel et al., 2006). In self-managed shelters,

participants have to work out the conflict themselves, and in the process develop social skills.

The fluid nature of self-management allows for more adaptation to participants needs and desires, which limits conflicts, in comparison to regular care offering one size fits all (Padgett et al., 2016; Van Regenmortel et al., 2006). Those participants unwilling to engage could benefit from JES, although JES did not benefit from their presence and to some extent, they demotivated other participants.

\section{Individual and collective empowerment}

Individual and collective empowerment were able to strengthen each other. Multiple participants developed skills through engaging in advocacy that benefited the program. In other cases, tensions occurred between individual and collective empowerment, for instance when a participant chose to focus on his individual situation, rather than advocate for the program. JES provided a limited number of roles, which participants would get pulled into when there was a management void and pushed away from when an informal core of leaders formed. Shelter size is likely to have an effect on the percentage of people finding meaningful roles (Brown et al., 2007). We spent less attention on collective empowerment in relation to other organizations and society.

The role-framework, enriched with insights from other authors (Maton, 2008; Peterson \& Zimmerman, 2004; Taylor, 1997), provided insights into how a self-managed shelter can contribute to participants' empowerment. A majority of participants say they benefited from the self-managed shelter, albeit in various ways. Being able to offer multiple opportunities for participants to develop empowerment, appears to be a strength of self-managed programs.

\section{Strengths and Limitations}


Understanding setting-empowerment

Our data is predominantly narrative, requiring reflective and verbal capacities, which risks underrepresentation of less verbal respondents (Bryman 2008). Participants who were less enthusiastic about JES are underrepresented in our data, caused by recruitment limitations. In our analysis and data presentation we emphasized an authentic representation, especially of less verbal and/ or critical participants, to counter underrepresentation, and to explore alternative and competing explanations (Abma et al., 2009). Non-verbal or more structured (less reflexive) data gathering in future research can triangulate our findings (Bryman 2008). A strength of our research is the first author's prolonged engagement with JES, combined with peer debriefings, which enabled him to observe developments over time, gain insight into the dynamics of selfmanagement and increase the representability of observations (Bryman 2008). Engagement of participants, peer workers and social workers increased our findings' authenticity (Lincoln and Guba 1985). In future work we will reflect more on our methodology and the role of researchers and participants in facilitating learning through our research.

\section{Practical Implications}

JES participants experienced freedom of choice and influence on the program they are living in, which they lacked in regular care. JES offered opportunities for social and organizational engagement, through which participants developed roles, skills and their selfimage. JES' fluid nature prevented rigid hierarchy and allowed participants to adapt the program to their desires and needs. Although participants benefited from JES in different ways, most participants preferred JES over regular shelters. JES participants aimed to access independent housing. JES contributed to this purpose, though housing scarcity demands societal and political action. 
Understanding setting-empowerment

The analysis as presented in this paper has been developed and discussed with JES representatives. Participants, peer workers and social workers maintain that in principle, each prospective participant should have the opportunity to find out for him- or herself whether selfmanagement is a fit. Emphasizing social support would go against individuals' freedom of choice and risk alienating participants who are weary of social relations. Our analysis helped articulate questions to ask prospective participants to help them make a more informed choice on whether to join, such as whether the prospective participant was able and willing to engage in individual and collective self-management and to take on the responsibilities that are part of selfmanagement. Our analysis offered participants, social workers and peer workers opportunities for reflection and insight and can offer other self-managed and similar programs into the level of individual freedom of choice they offer, balancing freedom of choice with support, offering opportunities for engagement and maintaining fluidity in program management to prevent hierarchy and limitations to participant' self-direction.

\section{Acknowledgements}

The empirical data for this paper gathered and analyzed as part of the Collaborative center for the social domain, financed by the Dutch government. Additional funds have been provided by care organizations. The authors would like to thank participants, peer workers, social workers, other stakeholders and other involved researchers for their contribution to designing and conducting this study.

\section{Conflict of interests}

The authors have no conflict of interest.

\section{References}

Abma, T. A. (2017). Participatie moet anders: van red jezelf naar erbij horen [Participation 
Understanding setting-empowerment

needs to change: from self-sufficiency to inclusion]. Sociale Vraagstukken.

https://www.socialevraagstukken.nl/participatie-moet-anders-van-red-jezelf-naar-erbijhoren/

Abma, T. A., Banks, S., Cook, T., Dias, S., Madsen, W., Springett, J., \& Wright, M. T. (2019). Participatory Research for Health and Social Well-Being. Springer. https://doi.org/10.1007/978-3-319-93191-3_13

Abma, T. A., Nierse, C. J., \& Widdershoven, G. A. M. (2009). Patients as Partners in Responsive Research: Methodological Notions for Collaborations in Mixed Research Teams.

Qualitative Health Research, 19(3), 401-415. https://doi.org/10.1177/1049732309331869

Abma, T. A., \& Stake, R. E. (2014). Science of the particular: An advocacy of naturalistic case study in health research. Qualitative Health Research, 24(8), 1150-1161. https://doi.org/10.1177/1049732314543196

Banks, S., Armstrong, A., Carter, K., Graham, H., Hayward, P., Henry, A., Holland, T., Holmes, C., Lee, A., McNulty, A., Moore, N., Nayling, N., Stokoe, A., \& Strachan, A. (2013). Everyday ethics in community-based participatory research. Contemporary Social Science, 8(3), 263-277. https://doi.org/10.1080/21582041.2013.769618

Barker, S. L., Maguire, N., Bishop, F. L., \& Stopa, L. (2018). Peer support critical elements and experiences in supporting the homeless: A qualitative study. Journal of Community \& Applied Social Psychology, 28(4), 213-229. https://doi.org/10.1002/casp.2353

Boone, K., Roets, G., \& Roose, R. (2019). Social work, participation, and poverty. Journal of Social Work, 19(3), 309-326. https://doi.org/10.1177/1468017318760789

Brown, L. D. (2012). Consumer-run mental health: Framework for recovery. Springer.

Brown, L. D., Shepherd, M., A. Wituk, S., \& Meissen, G. (2007). How settings change people: 
Understanding setting-empowerment

Applying behavior setting theory to consumer-run organizations. In Journal of Community Psychology (Vol. 35). https://doi.org/10.1002/jcop.20155

Brown, L. D., \& Townley, G. (2015). Determinants of engagement in mental health consumerrun organizations. Psychiatric Services (Washington, D.C.), 66(4), 411-417. https://doi.org/10.1176/appi.ps.201400150

Bryman, A. (2008). Social research methods. Oxford University Press.

Chandler, D., \& Torbert, B. (2003). Transforming Inquiry and Action: Interweaving 27 Flavors of Action Research. Action Research, 1(2), 133-152. https://doi.org/10.1177/14767503030012002

Denzin, N. K. (1989). The Research Act: A Theoretical Introduction to Sociological Methods (Third). Prentice-Hall.

Doyle, S. (2007). Member checking with older women: A framework for negotiating meaning. Health Care for Women International, 28(10), 888-908. https://doi.org/https://doi.org/10.1080/07399330701615325

Goffman, E. (1961). Asylums. Essays on the Social Situation of Mental Patients and other inmates. Anchor Books.

Hatzidimitriadou, E. (2002). Political ideology, helping mechanisms and empowerment of mental health self-help/mutual aid groups. Journal of Community \& Applied Social Psychology, 12(4), 271-285. https://doi.org/10.1002/casp.681

Kimchi, J., Polivka, B., \& Stevenson, J. S. (1991). Triangulation. Nursing Research, 40(6), 364366. https://doi.org/10.1097/00006199-199111000-00009

Lincoln, Y. S., \& Guba, E. G. (1985). Naturalistic Inquiry. Sage Publications.

Maton, K. I. (2008). Empowering community settings: Agents of individual development, 
Understanding setting-empowerment

community betterment, and positive social change. American Journal of Community

Psychology, 41(1-2), 4-21. https://doi.org/10.1007/s10464-007-9148-6

O’Reilly, K. (2012). Ethnographic methods [Second edition]. Routledge.

Ostrow, L., \& Croft, B. (2015). Peer Respites: A Research and Practice Agenda. Psychiatric Services, 66(6), 638-640. https://doi.org/10.1176/appi.ps.201400422

Padgett, D., Henwood, B. F., \& Tsemberis, S. J. (2016). Housing First: Ending homelessness, transforming systems, and changing lives. Oxford University Press, USA.

Peterson, N. A., \& Zimmerman, M. A. (2004). Beyond the individual: Toward a nomological network of organizational empowerment. American Journal of Community Psychology, 34(1-2), 129-145. https://doi.org/10.1023/B:AJCP.0000040151.77047.58

Rappaport, J. (1981). In praise of paradox. American Journal of Community Psychology, 9(1), 125.

Rappaport, J. (1987). Terms of empowerment/exemplars of prevention: Toward a theory for community psychology. American Journal of Community Psychology, 15(2), 121-148. https://doi.org/10.1007/BF00919275

Renedo, A., \& Marston, C. (2015). Spaces for Citizen Involvement in Healthcare: An Ethnographic Study. Sociology, 49(3), 488-504. https://doi.org/10.1177/0038038514544208

Rivest, M. P., \& Moreau, N. (2015). Between Emancipatory Practice and Disciplinary Interventions: Empowerment and Contemporary Social Normativity. British Journal of Social Work, 45(6), 1855-1870. https://doi.org/10.1093/bjsw/bcu017

Scott, S. (2010). Revisiting the total institution: Performative regulation in the reinventive institution. Sociology, 44(2), 213-231. https://doi.org/10.1177/0038038509357198 
Understanding setting-empowerment

Segal, S. P., \& Hayes, S. L. (2016). Consumer-run services research and implications for mental health care. Epidemiology and Psychiatric Sciences, 25(5), 410-416. https://doi.org/10.1017/S2045796016000287

Speer, P. W., \& Hughey, J. (1996). Mechanisms of Empowerment: Psychological Processes for Members of Power-based Community Organizations. Journal of Community \& Applied Social Psychology, 6(3), 177-187. https://doi.org/10.1002/(SICI)10991298(199608)6:3<177::AID-CASP368>3.0.CO;2-N

Taylor, J. B. (1997). Niches and practices: Extending the Ecological Perspective. In D. Saleebey (Ed.), The Strengths Perspective in Social Work Practice (2nd Edition) (pp. 214-227). Longman.

Trimbos. (2019). Maatschappelijke opvang : feiten en cijfers [Homeless care: facts and numbers]. https://www.trimbos.nl/kennis/maatschappelijke-opvang/maatschappelijkeopvang-feiten-en-cijfers

Tuynman, M., \& Huber, M. A. (2014). Maatschappelijke opvang in zelfbeheer [Self-managed homeless care]. Trimbos/HvA.

Van Der Laan, J., Van Straaten, B., Boersma, S. N., Rodenburg, G., van de Mheen, D., \& Wolf, J. R. L. M. (2018). Predicting homeless people's perceived health after entering the social relief system in The Netherlands. International Journal of Public Health, 63(2), 203-211. https://doi.org/10.1007/s00038-017-1026-X

Van Regenmortel, T. (2011). Lexicon van empowerment [Lexicon of empowerment]. Marie Kamphuis stichting.

Van Regenmortel, T., Demeyer, B., Vandenbempt, K., \& Van Damme, B. (2006). Zonder (t)huis [Without home]. LannooCampus. 
Understanding setting-empowerment

Wolins, M., \& Wozner, Y. (1982). Revitalizing residential settings. Jossey-Bass.

Zimmerman, M. A. (1995). Psychological empowerment: issues and illustration. American Journal of Community Psychology, 23(5), 581-599. 